\title{
28 Research Square \\ Medical studies during the COVID-19 pandemic: the impact of digital learning on burnout and mental health
}

Panagiotis Zis ( $\nabla$ zis.panagiotis@ucy.ac.cy)

Medical School, University of Cyprus

Artemios Artemiadis

Medical School, University of Cyprus

Panagiotis Bargiotas

Medical School, University of Cyprus

Antonios Nteveros

Medical School, University of Cyprus

Georgios M. Hadjigeorgiou

Medical School, University of Cyprus

\section{Research Article}

Keywords: Burnout, pandemic, COVID-19, medical studies, cynicism

Posted Date: August 21st, 2020

DOl: https://doi.org/10.21203/rs.3.rs-63097/v1

License: (9) This work is licensed under a Creative Commons Attribution 4.0 International License.

Read Full License 


\section{Abstract}

Objectives: The aim of this ecological study was to investigate what the impact of digital learning due to the COVID-19 pandemic was on the burnout and the overall mental health $(\mathrm{MH})$ of medical students.

Background: During the unprecedent era of COVID-19 pandemic, the majority of countries worldwide adopted very strong measurements. The universities closed their doors and the education continued through digital learning lectures.

Methods: An anonymous questionnaire was administered to all 189 eligible candidates before and during the COVID-19 pandemic. Mental health was assessed via the MH domain of the 36-item Short Form Health Survey (SF-36) and burnout with the Maslach Burnout Inventory - Student Survey (MBI-SS).

Results: Overall response rate was $81.5 \%$. The overall burnout prevalence did not differ significantly between the two periods (pre COVID-19 18.1\% vs COVID-19 18.2\%). However, the burnout prevalence dropped significantly in year 4 (pre COVID-19 40.7\% vs COVID-19 16.7\%, $\mathrm{p}=0.011$ ) whereas it increased significantly in year 6 (pre COVID-19 27.6\% vs COVID-19 50\%, $p=0.01$ ). When looking each MBI-SS dimension separately, we found that emotional exhaustion decreased significantly in year 4 but increased in year 6 and cynicism increased in all years. The overall $\mathrm{MH}$ deteriorated significantly between the two periods (pre COVID-19 58.8 \pm 21.6 vs COVID-19 48.3 $\pm 23, p<0.001$ ).

Conclusions: Digital learning in medical studies carries significant risks. Not only the $\mathrm{MH}$ deteriorates the cynicism levels increase. Emotional exhaustion increases particularly in final year students, who struggle with the lack of clinical experience just before they start working as qualified junior doctors.

\section{Background}

Burnout during medical studies is a phenomenon that increasingly gains attention on education research. Burnout plays a significant role in the overall well-being of medical students and has severe implications for the continuation of burnout during the residency period and even further [1].

During the unprecedent era of COVID-19 pandemic, the majority of countries worldwide adopted very strong measurements. The universities closed their doors and the education continued through digital learning lectures.

The aim of this ecological study was to investigate what the impact of digital learning due to the COVID19 pandemic was on the burnout and the overall mental health of medical students.

\section{Methods}

\section{Study design}


The Medical School Undergraduate Program runs for 6 years (three preclinical and three clinical years). In total 189 students are currently enrolled, all of which were invited to take part in the study. Originally the study was designed as a cross-sectional study before the COVID-19 pandemic and, thus, we had a baseline assessment (pre - COVID 19) which took place in January 2020. As the pandemic emerged in February 2020 and a subsequent lockdown and digital learning took place in March 2020 (including no clinical teaching for the clinical years 4-6) we performed a follow-up assessment in May 2020 (COVID19).

Patients or the public were not involved in the design, or conduct, or reporting, or dissemination plans of our research. The study was approved by the Cyprus National Bioethics Committee. All participants given written informed consent in order to participate.

\section{Assessments}

Mental health $(\mathrm{MH})$ was evaluated by the MH domain of the 36-item Short Form Health Survey (SF-36) [2]. Students answered the five items concerning their emotional well-being during the last four weeks in a 6-point Likert-type scale, ranging from 1 (all of the time) to 6 (never). Two items (e.g., "Have you been a happy person?") were reverse scored to ensure that a higher item value indicated better mental health. Then scores were transformed in a 0 to 100-point scale and averaged. Higher scores denoted better $\mathrm{MH}$. The instrument showed good reliability for this study (Cronbach's alpha $=0.88$ ).

Burnout. The Maslach Burnout Inventory - Student Survey (MBI-SS) was used to evaluate burnout among medical students [3]. Licenses to use MBI-SS were purchased via Mind Garden Inc. MBI-SS is a 16-item tool, with each item being rated on a 7-point Likert-type scale, ranging from 0 (never) to 6 (everyday). These items produce three subscales: exhaustion (EX), cynicism (CY) and efficacy (EF). As suggested by Schutte et al., one particular CY item ("When I'm in class or I'm studying I don't want to be bothered") removed because it was shown to be ambivalent and, thus, unsound [4]. The construct and concurrent (i.e. criterion-related) validity and the reliability this instrument were verified. The instrument showed good to excellent reliability for this study (Cronbach's alpha: $E X=0.92, C Y=0.87, E F=0.84$ ).

Burnout was defined as: a. EX score higher than the 75th percentile (21 for this study) and b. CY score higher than the 75 th percentile ( 5 for this study) or EF lower than the 25 th percentile ( 22 for this study), as previously suggested [5].

\section{Statistical analysis}

A database was developed using the Statistical Package for Social Science version 21.0 (Armonk, NY: IBM Corp). Frequencies (\%) were used to present data for the burnout prevalence. We applied binomial tests to compare burnout prevalence between the different COVID-19 periods, since medical students between each COVID-19 group were not completely independent neither matched. Within COVID-19 group comparisons for burnout prevalence across the medical years of education were made with chi-square test. Adjusted standardized residuals served to ascertain significant deviations from the expected 
frequencies. One sample Wilcoxon signed rank test was applied to compare $\mathrm{EX}, \mathrm{CY} \mathrm{EF}$, and $\mathrm{MH}$ between COVID-19 groups. The level of significance was 0.05 . The corrected $p$ value of 0.02 for six comparisons was used for all COVID-19 group comparisons across the medical years of education, according to the Benjamini-Yekutieli method.

\section{Results}

Of the 189 students, 182 participated to the baseline assessment (pre-COVID 19 response rate $96 . \%)$. Of those, 154 participated to the follow-up assessment (COVID 19 response rate $84.6 \%)$. Overall 154 (69.5\% females, mean age $22.6 \pm 4.1$ years) medical students participated in both assessments giving an overall response rate of $81.5 \%$.

The overall burnout prevalence among medical students did not differ significantly between the two periods (pre COVID-19 18.1\% vs COVID-19 18.2\%). However, a significant change of burnout prevalence was found when looking into each academic year separately. In particular, burnout prevalence dropped significantly in year 4 medical students whereas it increased significantly in year 6. (Table 1). When looking each MBI-SS dimension separately, we found that EX decreased significantly in year 4 but increased in year $6, \mathrm{CY}$ increased significantly in all years but year 4 and EF decreased significantly in year 4.

Table 1. Burnout prevalence $(\mathrm{n} / \mathrm{N}, \%)$ among medical students in different COVID-19 periods and academic years

\begin{tabular}{cccccccc} 
& Total & $1^{\text {st }}$ & $2^{\text {nd }}$ & $3^{\text {rd }}$ & $4^{\text {th }}$ & $5^{\text {th }}$ & $6^{\text {th }}$ \\
\hline $\begin{array}{c}\text { Students with } \\
\text { Burnout during } \\
\text { CovID-19 period }\end{array}$ & $\begin{array}{c}28 / 154 \\
(18.2)\end{array}$ & $0 / 18(0)$ & $\begin{array}{c}5 / 28 \\
(17.9)\end{array}$ & $\begin{array}{c}5 / 32 \\
(15.6)\end{array}$ & $\begin{array}{c}4 / 24 \\
(16.7)\end{array}$ & $\begin{array}{c}1 / 26 \\
(3.8)\end{array}$ & $\begin{array}{c}13 / 26 \\
(50)\end{array}$ \\
\hline $\begin{array}{c}\text { Students with } \\
\text { Burnout during }\end{array}$ & $33 / 182$ & $1 / 27$ & $6 / 33$ & $3 / 37$ & $11 / 27$ & $4 / 29$ & $8 / 29$ \\
pre CovID-19 & $(18.1)$ & $(3.7)$ & $(18.2)$ & $(8.1)$ & $(40.7)$ & $(13.8)$ & $(27.6)$ \\
period & & & & & & & \\
\hline Sig. ${ }^{1}$ & 0.5 & 0.507 & 0.5 & 0.108 & $0.011^{*}$ & 0.118 & $0.01^{*}$
\end{tabular}

${ }^{1}$ Binomial tests

${ }^{*} p \leq 0.02$ : Benjamini-Yekutieli corrected level of significance for six comparisons

The overall MH deteriorated significantly between the two periods (pre COVID-19 58.8 \pm 21.6 vs COVID-19 $48.3 \pm 23, p<0.001)$. When looking into the academic years separately, it deteriorated in all years and 
reached statistical significance in years 1, 3 and 6.

Figure 1 summarizes the changes observed in $\mathrm{MH}, \mathrm{EX}, \mathrm{CY}$ and $\mathrm{EF}$.

\section{Discussion}

The novelty of our study is that we examined what impact digital learning had in $\mathrm{MH}$ and burnout during the medical studies. We were able to perform this study as we had a baseline assessment only few weeks before the announcement of the strict measurements due to COVID-19 pandemic and we managed to reassess the students during the COVID-19 pandemic whilst the University still was offering only live electronic lectures. Our overall response rate was high (81.4\%), which strengthens our results. Although there was no significant difference on the overall burnout rate, there were two hidden messages when looking into the dimensions separately.

First, in all years CY levels increased. This dimension of MBI-SS assesses the views of students about their studies. Increased cynicism means that students doubt about the significance and usefulness of their studies and they become less interested or enthusiastic. A prerequisite for becoming a medical doctor is getting clinical experience, which cannot happen through electronic lectures or videos.

Second, different patterns were observed in the EX dimension. The emotional exhaustion reported by the $4^{\text {th }}$ year medical students decreased significantly whereas it increased significantly in the $6^{\text {th }}$ year students. This accounted for the change in the overall burnout rate when looking in each academic year separately; the rate dropped in $4^{\text {th }}$ year whilst it increased dramatically in the final year.

Previous research has shown a consistent pattern of increasing burnout after the initiation of the clinical exercise where students confront patients, disease and death [6 - 12]. In our School, clinical training begins at year 4 . When this direct contact stopped as a result of the digital learning we observed a decrease of burnout in those students. Contrary, at year 6 the opposite happened. A possible explanation for this is that those students are one step before becoming doctors. This uncertainty of the subsequent years as a professional along with the lack of clinical experience due to the digital learning just before qualifying are very burdensome.

\section{Conclusion}

Our study shows that digital learning in medical studies carries significant risks for the students. Not only the $\mathrm{MH}$ deteriorates but the lack of direct interaction with the teachers and the clinical tutors increase the $\mathrm{CY}$ levels. Particularly final year students, struggle with the lack of clinical experience just before they start working as qualified junior doctors.

\section{Abbreviations}

COVID, corona-virus disease 
SF-36, 36-item Short Form Health Survey

MBI-SS, Maslach Burnout Inventory - Student Survey

EX, exhaustion

CY, cynicism

$E F$, efficacy

\section{Declarations}

\section{Ethics approval and consent to participate}

The study was approved by the Cyprus National Bioethics Committee. All participants given written informed consent in order to participate.

Consent for publication

Not applicable

\section{Availability of data and material}

All databases are available from the corresponding author upon reasonable request.

\section{Competing interests}

Not applicable

\section{Funding}

This was an unfunded study

\section{Authors' contributions}

PZ and AA: drafting/revising the manuscript, data collection.

PB and GH: drafting/revising the manuscript, accept responsibility for conduct of research and final approval

AN: drafting/revising the manuscript, accept responsibility for conduct of research and final approval.

\section{Acknowledgements}

None 


\section{References}

1. Ishak W, Nikravesh R, Lederer S, Perry R, Ogunyemi D, Bernstein C. Burnout in medical students: a systematic review. The clinical teacher. 2013 Aug;10(4):242-5.

2. Hays RD, Sherbourne CD, Mazel RM. The rand 36-item health survey 1.0. Health economics. 1993 Oct;2(3):217-27.

3. Schaufeli WB, Martinez IM, Pinto AM, Salanova M, Bakker AB.. Burnout and engagement in university students: a cross-national study. J Cross-Cult Psychol. 2002;33:464-481.

4. Schutte N, Toppinen S, Kalimo R, Schaufeli W. The factorial validity of the Maslach Burnout Inventory-General Survey (MBI-GS) across occupational groups and nations. Journal of Occupational and Organizational psychology. 2000 Mar;73(1):53-66.

5. Zis P, Artemiadis AK, Lykouri M, Xirou S, Roussopoulou A, Papageorgiou E, Bakola E, Anagnostopoulos F. Residency training: determinants of burnout of neurology trainees in Attica, Greece. Neurology. 2015 Sep 15;85(11):e81-4.

6. Paro HBMS, Silveira PSP, Perotta B, Gannam S, Enns SC, Giaxa RRB, et al. Empathy among medical students: Is there a relation with quality of life and burnout? PLoS One. 2014;9(4).

7. Fitzpatrick O, Biesma R, Conroy RM, McGarvey A. Prevalence and relationship between burnout and depression in our future doctors: A cross-sectional study in a cohort of preclinical and clinical medical students in Ireland. BMJ Open. 2019;9(4).

8. Santen SA, Holt DB, Kemp JD, Hemphill RR. Burnout in medical students: Examining the prevalence and associated factors. South Med J. 2010;103(8):758-63.

9. Voltmer E, Rosta J, Aasland OG, Spahn C. Study-related health and behavior patterns of medical students: a longitudinal study. Med Teach. 2010;32:422-e428

10. Chang E, Eddins-Folensbee F, Coverdale J. Survey of the prevalence of burnout, stress, depression, and the use of supports by medical students at one school. Acad Psychiatry. 2012;36:177-182.

11. Cecil J, McHale C, Hart J, Laidlaw A. Behaviour and burnout in medical students. Med Educ Online. 2014;19(April):25209.

12. Scholz M, Neumann C, Steinmann C, Hammer CM, Schroder A, Essel N, Paulsen F, Burger PH. Development and correlation of work-related behavior and experience patterns, burnout and quality of life in medical students from their freshmanship to the first state examination. Psychother Psychosom, Med Psychol. 2015;65:93-98.

\section{Figures}



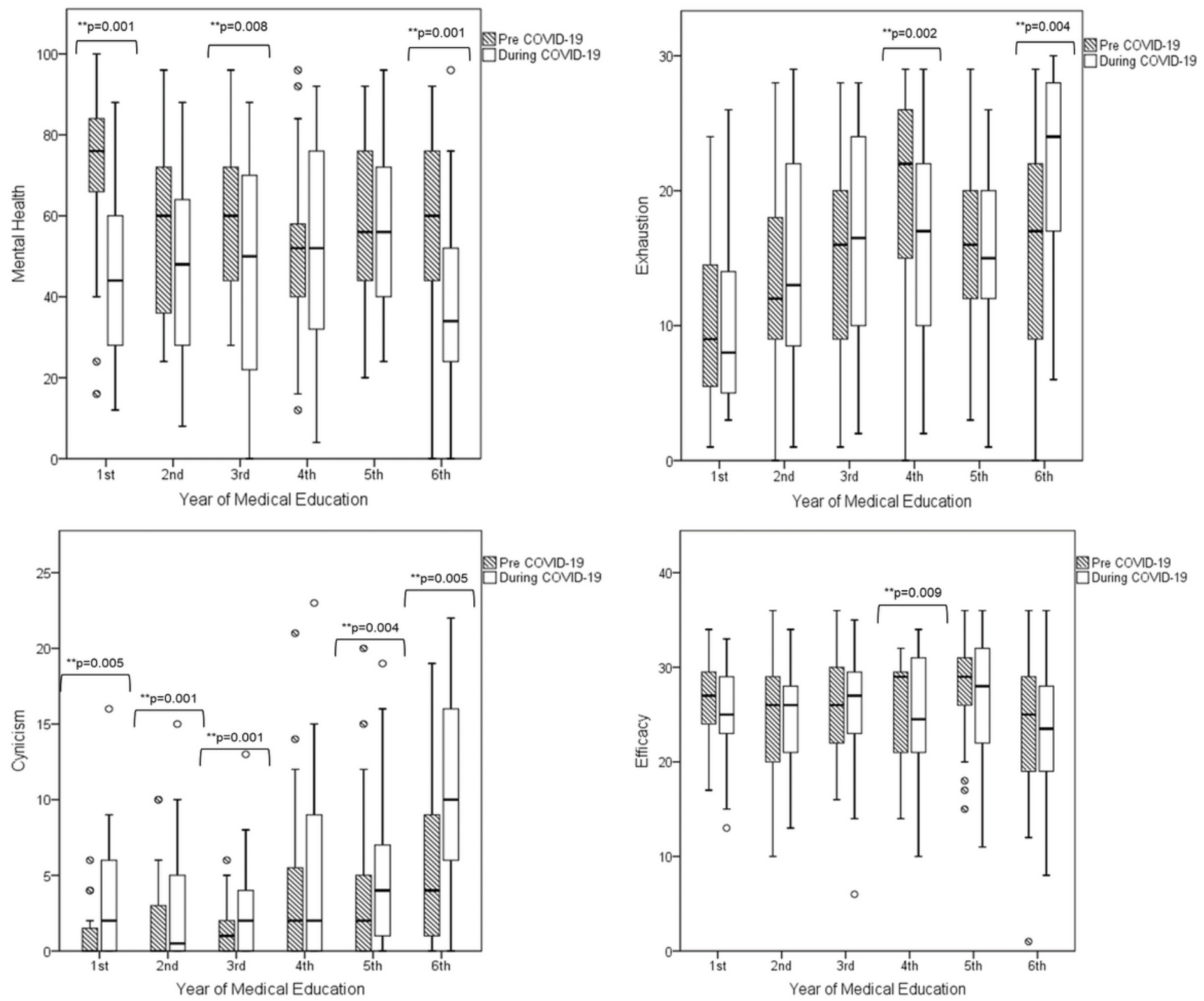

Figure 1

Changes observed in Maslach Burnout Inventory Student Survey dimensions and overall Mental Health after implementing digital learning.

\section{Supplementary Files}

This is a list of supplementary files associated with this preprint. Click to download.

- burnoutcovid.sav 